\title{
Measuring Multidimensional Child Poverty in the Era of the Sustainable Development Goals
}

\author{
Yekaterina Chzhen $^{1}$ (D) David Gordon ${ }^{2}$. \\ Sudhanshu Handa ${ }^{3}$
}

Accepted: 14 July 2017 / Published online: 23 August 2017

(C) Springer Science+Business Media B.V. 2017

The new global Sustainable Development Goals (SDGs), agreed to by governments of the world in 2015, present an unprecedented opportunity for social progress for the new generation of children and young people (UNICEF and Global Coalition to End Child Poverty 2017). Goal 1 calls for "reducing at least by half the proportion of men, women and children of all ages living in poverty in all its dimensions according to national definitions" (Target 1.2) by 2030 (United Nations 2015). The wording of Target 1.2 is significant because for the first time a global poverty goal includes children explicitly and recognizes the multidimensional nature of poverty. It is also the first time that a global poverty goal applies equally to rich and poor countries and refers explicitly to national definitions.

While child poverty is still often measured as the share of children living in incomeor consumption-poor households (Cantillon et al. 2017; Davis et al. 2016), it is by now widely recognized that household-based monetary metrics do not capture what it means for a child to be poor (Main and Bradshaw 2016). The equivalence scales used to adjust for household size and composition make assumptions about children's share of household resources (Roelen and Gassmann 2008), but in practice we know little about intra-household resource allocation, and children may not participate or have much say in decisions about how resources are allocated (Feeny and Boyden 2004; Main 2017). Moreover, monetary resources alone are insufficient to fulfil all of children's needs because some of the goods and services that are of importance for child development do not always have competitive markets (e.g. health, education, water and sanitation) or any markets at all (e.g. protection from violence) (Chzhen and Ferrone 2017).

Yekaterina Chzhen

ychzhen@unicef.org

1 UNICEF Office of Research - Innocenti, Piazza SS Annunziata 12, 50122 Florence, Italy

2 Social Science Complex, University of Bristol, 8 Priory Road, Bristol BS8 1TZ, UK

3 Abernethy Hall, University of North Carolina at Chapel Hill, CB\#3435, Chapel Hill, NC 27599-3435, USA 
Although research on multidimensional child poverty has taken off in recent years, there is no global child-specific estimate of the number of multidimensionally poor children (UNICEF and Global Coalition to End Child Poverty 2017) as the estimates of Gordon et al. (2003) are only for developing countries. Nor is there consensus around a common conceptual or normative framework for measuring multidimensional child poverty. This Special Issue helps to fill these gaps by providing regional and national estimates of multidimensional child poverty across a diverse range of low-, middle- and high-income countries. It includes five studies that use a versatile Multiple Overlapping Deprivation Analysis (MODA) methodology developed by the UNICEF Office of Research (de Neubourg et al. 2012) that has a strong normative element and can be flexibly applied to different contexts. It also includes a study on multidimensional child poverty in the European Union (EU). Both MODA and the EU paper draw on Townsend's theory of Relative Deprivation. However, the EU paper adopts a sociological Consensual Deprivation approach whereas MODA is rooted in the children's rights framework which puts the child at the centre of analysis. All six papers define indicators and dimensions of child poverty using mainly child-specific items, although a few, such as housing quality, are measured at the level of the household. MODA and Consensual Deprivation methods can be adapted to both national and cross-country comparative contexts. Three of the studies in this Special Issue report the results of national MODA studies and three focus on cross-country comparisons.

Marlous de Milliano and Ilze Plavgo estimate the number of multidimensionally poor children in thirty Sub-Saharan African countries, using comparable data and similar definitions of poverty. Their paper illustrates how one can define dimensions and indicators at a regional level to obtain comparable, cross-country and regional estimates of child multidimensional poverty, an approach that would be of interest to regional political and economic bodies such as the African Union. Lucia Ferrone and Marlous de Milliano then present the results of national MODA studies in three of these countries - Mali, Malawi and Tanzania - reflecting on the different consultative processes that led to the adoption of indicators and dimensions of poverty tailored to the local contexts. Lucia Ferrone and Yekaterina Chzhen provide a similar analysis for two middle-income countries - Armenia and Bosnia and Herzegovina - simulating alternative strategies for halving the multidimensional child poverty rate in order to achieve the SDG Target 1.2. Meanwhile, Kolbeinn Stefánsson, Lovísa Arnardóttir and Anton Örn Karlsson analyse the impact of the Great Recession on multidimensional child poverty in Iceland using data from the ad-hoc material deprivation modules from the European Union Statistics on Income and Living Conditions (EU-SILC) 2009 and 2014. It is the first national MODA study in a high-income country, resulting from a collaboration between UNICEF Iceland and Statistics Iceland. Taken together, these three papers illustrate how the MODA approach can be 'domesticated' in very different settings to reflect national values about child multidimensional poverty. AnneCatherine Guio, David Gordon, Eric Marlier, Hector Najera and Marco Pomati propose a new multidimensional measure of child material and social deprivation (MSD) for the $28 \mathrm{EU}$ member states which includes age appropriate child-specific information from the EU-SILC. They adapt the UK Poverty and Social Exclusion project methodology to produce a suitable, valid, reliable and additive index which produces comparable results in each country. Finally, Yekaterina Chzhen, Zlata Bruckauf, Emilia Toczydlowska, Frank Elgar, Concepcion Moreno-Maldonado, Gonneke Stevens, 
Dagmar Sigmundová and Geneviève Gariepy apply the MODA methodology to 37 European countries and Canada using data on adolescents aged 11, 13 and 15 from the 2013/14 Health Behaviour in School-aged Children survey. They focus on non-material, relational aspects of deprivation, finding higher rates of multidimensional poverty among girls than boys in the majority of the countries studied. The importance of this analysis is its focus on adolescents, and the definition of dimensions and indicators that capture key components of their well-being (e.g. mental health; protection from peer violence).

Together these articles provide a set of examples for researchers and state parties on how to approach the measurement and monitoring of child multidimensional poverty as part of their commitment towards SDG Target 1.2.

\section{References}

Cantillon, B., Chzhen, Y., Handa, S., \& Nolan, B. (2017). Children of austerity: The impact of the great recession on child poverty in rich countries. Oxford: Oxford University Press.

Chzhen, Y., \& Ferrone, L. (2017). Multidimensional child deprivation and poverty measurement: Case study of Bosnia and Herzegovina. Social Indicators Research, 131(3), 999-1014.

Davis, B., Handa, S., Hypher, N., Winters, P., Rossi, N. W., \& Yablonski, J. (2016). From evidence to action: The story of cash transfers and impact evaluation in sub Saharan Africa. Oxford: Oxford University Press.

de Neubourg, C., Chai, J., de Milliano, M., Plavgo, I., \& Wei, Z. (2012). Step-by-step guidelines to the multiple overlapping deprivation analysis (MODA). Innocenti Working Paper, WP-2012-10, UNICEF Office of Research.

Feeny, T., \& Boyden, J. (2004). Acting in adversity: Rethinking the causes, experiences and effects of child poverty in contemporary literature. Literature and thought on Children and Poverty", in Children and Poverty Series Working Paper, 116.

Gordon, D., Nandy, S., Pantazis, C., Pemberton, S., \& Townsend, P. (2003). The distribution of child poverty in the developing world. Bristol: Centre for International Poverty Research.

Main, G. (2017). Child poverty and subjective well-being: The impact of children's perceptions of fairness and involvement in intra-household sharing. Children and Youth Services Review. https://doi.org/10.1016/j.childyouth.2017.06.031.

Main, G., \& Bradshaw, J. (2016). Child poverty in the UK: Measures, prevalence and intra-household sharing. Critical Social Policy, 36(1), 38-61.

Roelen, K., \& Gassmann, F. (2008). Measuring child poverty and well-being: A literature review. Maastricht Graduate School of Governance Working Paper Series No, 2008/WP001.

UNICEF, \& Global Coalition to End Child Poverty. (2017). A world free from child poverty: A guide to the tasks to achieve the vision. New York: UNICEF and the Global Coalition to End Child Poverty.

United Nations. (2015). Transforming our world: The 2030 agenda for sustainable development. New York: United Nations General Assembly. 